\title{
COVID-19 and Depression: Prevalence and Risk Factors in Youth from Maharashtra, India
}

\author{
Mini Narayanan ${ }^{1}$ (D) $\cdot$ Sujata Sriram²
}

Received: 1 July 2021 / Revised: 17 September 2021 / Accepted: 18 September 2021

(c) The Author(s), under exclusive licence to Springer Nature Switzerland AG 2021

\begin{abstract}
The COVID-19 pandemic and the ensuing lockdown have been a seismic shock for youth in India, elevating their risk of mental health problems like depression. This cross-sectional study sought to measure the point prevalence levels of depression in university students (ages 19-25 years) from Maharashtra, India, during the peak of the first wave of the pandemic and lockdown, through an online opt-in survey. The BDI-II was self-administered by 783 respondents (males $=243$; females $=540$ ). Results indicated overall mild levels of depression (mean BDI $=16.48)$ and high point prevalence, with $51.8 \%(n=406)$ of the population being symptomatic, of which $16.3 \%$ had severe, $17.9 \%$ had moderate, and $17.8 \%$ had mild levels of depression. No association was found with age, gender, educational level of participants, period of hostel stay, education, and occupational level of parents. Overall percentages of symptomatic women were higher, suggesting the gendered effects of the pandemic. This study explored the symptomatology of depression wherein "sadness," "changes in sleep patterns," and "concentration difficulties" emerged as the most commonly experienced symptoms. Symptom expression was found to vary with intensity and gender. Symptomatic men experienced significantly more cognitive symptoms like self-criticalness, punishment feelings, thoughts about past failures, and changes in sleep patterns, while symptomatic women felt significantly high "loss of energy." No significant gender differences were seen in the experience of cognitive-affective symptoms. Possible reasons are discussed. Further exploration of the experiences of youth is essential to understand the full gamut of the pandemic's impact on them.
\end{abstract}

Keywords Depression $\cdot$ Youth $\cdot$ India $\cdot$ Pandemic $\cdot$ Lockdown $\cdot$ Maharashtra

Depression in youth is one of the most commonly diagnosed mental health disorders in primary care practice the world over, with a global lifetime prevalence of 15 to $20 \%$ (Kaur

Mini Narayanan

mnarayanan@mum.amity.edu; minianoop@gmail.com

Sujata Sriram

sujatasriram@gmail.com; sujatas@tiss.edu

1 Amity Institute of Behavioral and Allied Sciences, Amity University, Mumbai, Maharashtra, India

2 School of Human Ecology, Tata Institute of Social Sciences, Deonar, Mumbai, Maharashtra, India 
et al., 2014), and has been declared a priority mental health disorder by the World Health Organization (WHO). Depression occurring during this life stage is associated with various physiological and psychological comorbidities (irritable bowel syndrome, pain, cancers, osteoporosis, substance abuse, anxiety, truancy, risk-taking behaviors, self-harm) that have a ripple effect on several important biopsychosocial aspects of the growing adolescent's life. In India, depression is the leading non-fatal disease burden on youth and the primary disruptor of their development, education, and growth. It is the primary source of disability-adjusted life years (DALYs), contributing to challenging economic consequences for self and family (Arvind et al., 2019; Sagar et al., 2020).

A significant precipitating factor in the etiology of depression is repeated exposure to stressful life events (Yang et al., 2015). In the aftermath of the COVID-19 pandemic, which hit the world in November 2019, several countries of the world adopted strict lockdowns, quarantine measures, and norms for social distancing. In India, a nationwide lockdown was introduced on $24^{\text {th }}$ March 2020. While different sections of society experienced the crisis differently, for young people particularly, this has been a period of chaos and tumult. The pandemic-induced lockdown disrupted academic activities and outcomes, occupational opportunities, physical and psychological safety, income stability, socialization practices, individual freedom, and lifestyle habits (Lianhmingthangi et al., 2020; Özdin \& Özdin, 2020; Salari et al., 2020). Social isolation, increased screen time, falling academic confidence and performance, heightened future uncertainty, overwork, gaming addiction, poor sleep quality, parental anxiety, increased family violence, and home confinement were some of the reported effects of the pandemic on Indian youth (Jacob et al., 2020; John \& John, 2021; Patra \& Patro, 2020). The cascading effect of this sustained health crisis is expected to exacerbate problems like depression and anxiety, particularly among those in a developmentally sensitive period (Courtney et al., 2020; Porter et al., 2021).

In India, despite the growing disease burden of depression on youth, systematic national and state-level data related to it are limited and often riddled with discrepancies (Arvind et al., 2019; Grover et al., 2010). The NMHS survey (2016), one of the most elaborate and detailed analyses of mental health indicators of the Indian population based on information from 12 geographically and culturally diverse states, found a point prevalence rate of $2.6 \%$ for depressive disorders among youth. Independent studies from different states have found much higher prevalence rates ranging from 40\% in Chandigarh, 47.9\% in New Delhi, and $49.2 \%$ in Patna, Bihar, to $52.9 \%$ in Rohtak, Haryana, and $71.3 \%$ in Bhopal (Madhya Pradesh) (Kumar et al., 2019; Malik et al., 2015; Singh et al., 2017). Similar variations were seen in studies from South India as well, with prevalence rates ranging from $39 \%$ in rural Karnataka and $43 \%$ in North Kerala to $57.6 \%$ in urban Mangalore (Shaikh et al., 2018; Hanspal et al., 2019; Pandian et al., 2017; Shelke et al., 2015; Urmila et al., 2017). Indian studies exploring risk factors associated with depression also report inconsistent findings, with some studies finding linkages with socio-demographic factors like age, feminine gender, adverse life events, literacy rates, academic stress, and occupation of one or both parents (Hanspal et al., 2019; Lodha et al., 2016; Shaikh et al., 2018), while others find contrasting or no linkages between depression and such contextual factors (Mohanraj \& Subbaiah, 2010; Rezvan \& D'Souza, 2017; Shaikh et al., 2018; Shelke et al., 2015).

Variations, as mentioned above, have been previously reported in studies from India and elsewhere in the world (Ayuso-Mateos et al., 2001; Grover et al., 2010) and have been attributed to diversity in population, plurality in contexts, characteristics of samples, and variations in operationalization, methodological, and sampling techniques (Arvind et al., 
2019; Grover et al., 2010). Existing inconsistencies in findings from Indian youth point to the fact that data collected from various states may not be sufficiently representational of the youth of the entire country. Instead, it may be more useful and precise to gather areaspecific data to arrive at prevalence rates for a particular socio-demographic, geographical context. Real-time data becomes particularly relevant during the current COVID-19 pandemic as the impact of the pandemic is predicted to depend on factors such as the stage of the pandemic, age, and personality characteristics of the individual and contextual factors, like socioeconomic strata and gender (Courtney et al., 2020).

The current study was part of a larger doctoral study to explore the association between depression and differentiation of self in youth. After receiving ethical clearance from the review board, data collection was carried out in November 2020, at the peak of the COVID-19 pandemic when the national lockdown was in place in India. This study can fill the gap in literature by providing information regarding prevalence rates of depression in Maharashtra at the peak of the first wave of the pandemic, when youth were under lockdown conditions and following COVID norms for about 6 months.

Symptom clusters in depression fall along a wide range of cognitive-affective (sadness, pessimism, loss of interest, and suicidal ideation) and somatic (changes in appetite, loss of energy, changes in sleep patterns, loss of interest in sex, fatigue, and physical discomfort) dimensions (Al-Turkait \& Ohaeri, 2010). The experience of these symptoms and their management are mediated by various factors like age, geography, social, and cultural contexts. The nature of symptoms experienced by young people has predictive value in the early diagnosis of clinical depression and requires deeper exploration (Dardas et al., 2016). Very few studies have reported the symptom profile of depression among Indian youth, and most of the data is based on clinical samples and collected retrospectively. Due to this, we know very little about symptom expression of depression in non-clinical university students. Since data for this study was collected during the lockdown period, when educational institutions and offices were functioning through online modes, the nature of symptoms that youth were experiencing at this time and significant patterns that emerge will offer greater insight into their experience of depression during this period. Evidencebased data emerging from such studies can help policymakers, mental health professionals, educators, and parents develop plans, programs, and strategies to mitigate the burden of depression among youth.

\section{Methodology}

\section{Definition of "Youth"}

"Youth" is a term of great plasticity. The WHO defines youth as people between the ages of 15 and 24 years, while the National Youth Policy of India (2003) refers to individuals between 15 and 35 years as "youth." Arnett (2000) identified the period between 18 and 25 years as "emerging adulthood" when several key transitions are made by the individual. These years of an individual's life are crucial because they are highly volitional and facilitate identity exploration in the areas of love, work, and worldviews. In this paper, the term "youth" refers to individuals between 19 and 25 years of age. 


\section{Maharashtra}

The sample for this paper is drawn from Maharashtra, which also consists of the port city of Mumbai (capital city of Maharashtra) as well as the districts of Thane and Pune. The state has a literacy rate of $77.3 \%$ and attracts a large number of students from all over India and the world, making many of its universities and colleges culturally and linguistically varied.

\section{Sampling}

This cross-sectional survey was conducted in colleges across various universities in Maharashtra during the month of November 2020, when the national lockdown was in place in Maharashtra due to the COVID-19 pandemic. At this time, colleges and universities were holding classes online and social interactions were severely curtailed. An internet-based survey was conducted using convenient snowball sampling. Youth aged 19-25 years who were registered in colleges across Maharashtra for any full-time course and had access to a stable internet connection were eligible to participate in the study and self-administer the questionnaire. Participants were sent the voluntary opt-in online form through several student groups using social media platforms. The survey was set up such that it was mandatory to answer all questions and only one response was allowed. The final sample of the study consisted of 783 participants. There were no incomplete responses.

\section{Ethical Considerations}

Adherence to ethical guidelines is vital when carrying out research in the area of mental health issues because of diagnostic issues, associated myths, stigma, biases, and paucity of treatment options in India (Jain et al., 2017). Ethical approval for the study was obtained from the Institutional Review Board of the Tata Institute of Social Sciences, Mumbai. The objectives and possible uses of the study were shared with participants before they consented to participate. Participants were also provided with a care packet containing information about depression, symptoms, self-care, and details regarding how to access mental health care from professionals, if required. The online form allowed participants to proceed to the questionnaire only after they had accessed the care packet and provided consent to participate in the study. Participant details were anonymized to ensure confidentiality. No personal identifiers were disclosed anywhere during the analysis of data.

\section{Materials and Methods}

The dependent variable of this study was depression, and it was measured using the Beck Depression Inventory-II (BDI-II), one of the most frequently used self-report measures of syndrome depression. The BDI-II (Beck et al., 1996) is a revised version of the original tool and consists of 21 questions assessing cognitive, affective, and somatic symptoms of depression as experienced in the last 2 weeks. On a non-clinical population, a single administration of the BDI-II in the absence of other diagnostic assessments may not indicate clinically diagnosable disorders, but scores may still be used to screen for probable cases of depressive symptoms as operationalized in the fourth 
edition of the Diagnostic and Statistical Manual (DSM)-IV (Wang \& Gorenstein, 2013). The scale is easy to administer and has high content and construct validity and shows concurrent validity with other measures like the MMPI (Minnesota Multiphasic Personality Inventory) and the Hamilton Depression Rating Scale. It has been used in several Indian studies to measure the levels of depression in Indian adolescents (Win et al., 2019), thereby demonstrating its cross-cultural compatibility with the target population. The scale has an internal consistency of 0.9 and high test-retest reliability. Although some studies indicate different scores for symptom categories depending on whether the sample is drawn from a clinical or non-clinical population, the current study used the recommended cut-off scores of the original scale to classify participants into minimal (0-13), mild (14-19), moderate (20-28), and severe (29-63) intensities of depression (Beck et al., 1988). Existing factor models and item content of the BDI-II draw a distinction between cognitive-affective symptoms of depression (items 1-14: sadness, pessimism, past failure, loss of pleasure, guilty feelings, punishment feelings, self-dislike, self-criticalness, suicidal ideation, crying, agitation, loss of interest, indecisiveness, worthlessness) and somatic symptoms (items 15-21: loss of energy, sleep problems, irritability, appetite problems, concentration, fatigue, loss of interest in sex). Sociodemographic data were collected from participants, as indicated in Table 1.

Data were analyzed using SPSS version 21.0. Socio-demographic characteristics and prevalence of depressive symptoms were represented using descriptive statistics. Associations between prevalence and related aggravating factors were analyzed using the Chi-square test of independence. Statistical analyses were carried out at a $P$-value of $<0.05$ or a $95 \%$ confidence interval. In order to analyze the pattern of symptoms of depression, scores of individual items were extracted. A score of " 1 " or above on any item was considered to indicate the presence of the symptom. The percentage of people with symptoms was calculated to determine the prevalence of the symptom.

Data for this study was collected online. There exists evidence that online research may sometimes not yield valid data if seriousness checks are not incorporated into the questionnaire (Aust et al., 2013; Ward \& Pond, 2015). In this study, the form was designed to prevent non-responses and ensure single responses wherever applicable. Difficult to understand words were explained in brackets within the question to help participants answer questions appropriately. However, there were no seriousness checks incorporated, which may call to question the validity of responses. Before analysis, the

Table 1 Socio-demographic data collected from participants

\begin{tabular}{ll}
\hline Gender & Male, Female \\
\hline Highest level of education & $\begin{array}{r}\text { Professional, Post-graduation, Graduation, Higher Secondary (Grade 11 } \\
\& \text { 12), Secondary School (Grade 10) }\end{array}$ \\
$\begin{array}{l}\text { Birth position } \\
\text { Nature of family }\end{array}$ & $\begin{array}{l}\text { Single, Youngest, Oldest, Somewhere in the middle } \\
\text { parents, Parents and extended family, Extended family, Stepparents }\end{array}$ \\
Relationship status & $\begin{array}{l}\text { Single, In a casual relationship, In a committed relationship } \\
\text { Having stayed in a hostel facility } \\
\text { Period of stay in hostel }\end{array}$ \\
$\begin{array}{l}\text { Yes, No } \\
\text { Educational level of each parent } \\
\text { Occupation of each parent }\end{array}$ & $\begin{array}{l}\text { Schooling, Graduate, Post-graduate } \\
\text { Self-employed, Employed, Unemployed, Retired (in case of mothers, } \\
\text { Homemaker) }\end{array}$ \\
\hline
\end{tabular}


data were checked for similar, extreme, or neutral responses across questions. No such records were found.

\section{Results}

\section{Participant Profile}

A total of 788 youth responded to the survey. Three participants opted not to complete the survey and were not included in the analysis. Two participants mentioned their gender as "Other" from the available options of "Male," "Female," and "Other." Due to the lack of representativeness of the sample who identified themselves as "Other" $(n=2)$, their data were not included in the analyses. The final data for analysis included 783 youth who fell into the "Male" or "Female" gender categories. It was seen that $31 \%(n=243)$ of the participants were identified as male, and 69\% $(n=540)$ were female. The mean age of the sample was 20.77 years. Findings related to socio-demographic features of the sample are presented in Table 2 .

Bivariate analysis was performed to find out if there existed a relationship between depression and socio-demographic factors. The dependent variable (depression scores) was not normally distributed (Skewness $=0.79$; Kurtosis $=0.09$ ) as indicated by the Kolmogorov-Smirnov test $(\mathrm{D}(783)=0.098, p=0.00)$. The visual representation of the histogram showed positively skewed data, and the Q-Q plot also did not cluster around the trend line. As the data was not normally distributed, the Kruskal-Wallis test was used to compare means.

\section{Prevalence}

Standard cut-off scores on BDI-II $(B D I>=14)$ indicated the prevalence of depressive symptoms in $51.8 \%$ of the population ( $n=407)$, consisting of 118 males and 288 females. $17.8 \%(n=139)$ of the symptomatic population had mild levels, $17.9 \%(n=140)$ had moderate levels, and $16.3 \%(n=128)$ had severe levels of depression. The mean BDI score of the sample was $16.48(\mathrm{SD}=11.58)$ (Table 3$)$.

\section{Descriptive Statistics}

Depression was not found to be significantly associated with socio-demographic factors like educational qualifications, nature of family, birth position, relationship status, hostel stay, parental education, or occupational status. Depression was also not significantly associated with gender (Table 4). Although there were more females than males in each of the symptom categories, there were no significant differences in levels of depression $(p=0.107)$ between genders.

\section{Symptomatology}

Symptom expression of depression was found to vary with intensity. The top five most commonly experienced somatic symptoms across mild, moderate, and severe categories were changes in sleep patterns, difficulties in concentration, loss of energy, changes in 
Table 2 Socio-demographic characteristics of participants

\begin{tabular}{|c|c|c|}
\hline Characteristic & $(n)$ & $(\%)$ \\
\hline \multicolumn{3}{|l|}{ Birth position } \\
\hline Youngest & 263 & 33.6 \\
\hline Single & 143 & 18.3 \\
\hline Middle & 68 & 8.7 \\
\hline Oldest & 309 & 39.5 \\
\hline \multicolumn{3}{|l|}{ Level of education } \\
\hline SSc_10 & 3 & 0.4 \\
\hline HSc_12 & 273 & 34.9 \\
\hline Graduate & 365 & 46.6 \\
\hline Post-Grad & 87 & 11.1 \\
\hline Professional & 55 & 7.0 \\
\hline \multicolumn{3}{|l|}{ Relationship status } \\
\hline Single & 550 & 70.2 \\
\hline Casual & 39 & 5.0 \\
\hline Committed & 194 & 24.8 \\
\hline \multicolumn{3}{|l|}{ Hostel stay period } \\
\hline $0-3$ months & 509 & 65 \\
\hline $3-12$ months & 95 & 12.1 \\
\hline $12-24$ months & 78 & 10 \\
\hline 24-36 months & 55 & 7 \\
\hline 36 months + & 46 & 5.9 \\
\hline \multicolumn{3}{|c|}{ Father's education \& occupation } \\
\hline FatherSchool & 254 & 32.4 \\
\hline FatherGrad & 330 & 42.1 \\
\hline FatherPostGrad & 199 & 25.4 \\
\hline FatherUnempl & 23 & 2.9 \\
\hline FatherSelfEmp & 312 & 39.8 \\
\hline FatherEmpl & 375 & 47.9 \\
\hline FatherRetired & 73 & 9.3 \\
\hline \multicolumn{3}{|c|}{ Mother's education \& occupation } \\
\hline MotherSchool & 294 & 37.5 \\
\hline MotherGrad & 327 & 41.8 \\
\hline MotherPostGrad & 162 & 20.7 \\
\hline MotherUnempl & 8 & 1.0 \\
\hline MotherSelfEmp & 91 & 11.6 \\
\hline MotherEmpl & 177 & 22.6 \\
\hline MotherRetired & 16 & 2.0 \\
\hline MotherHomeMkr & 491 & 62.7 \\
\hline
\end{tabular}

appetite, and tiredness, while the most commonly experienced cognitive-affective symptoms were sadness, loss of interest, feelings of guilt, loss of pleasure, and irritability. However, when taking only the moderate and severe categories into consideration, the experience of somatic symptoms like changes in sleep patterns, concentration difficulties, loss of energy, and fatigue surpassed the experience of other cognitive-affective symptoms 
Table 3 Bivariate analysis of socio-demographic characteristics of participants by gender

\begin{tabular}{|c|c|c|c|c|c|c|c|c|c|}
\hline \multirow[t]{2}{*}{ Factor } & \multicolumn{4}{|c|}{ Males $(n=243)$} & \multicolumn{4}{|c|}{ Females $(n=540)$} & \multirow[t]{2}{*}{ Dep } \\
\hline & $n$ & $\%$ & Mean & SD & $n$ & $\%$ & Mean & SD & \\
\hline \multicolumn{10}{|c|}{ Age (yr) } \\
\hline 19 & 74 & 30 & 16.08 & 10.4 & 151 & 28 & 17.98 & 11.7 & 0.57 \\
\hline 20 & 57 & 23 & 14.75 & 12.3 & 128 & 23 & 17.03 & 11.5 & 0.5 \\
\hline 21 & 46 & 19 & 16.65 & 13.5 & 84 & 16 & 14.58 & 09.8 & 0.48 \\
\hline 22 & 27 & 11 & 17.44 & 13.2 & 80 & 15 & 16.59 & 11.3 & 0.57 \\
\hline 23 & 19 & 08 & 14.95 & 11.4 & 62 & 11 & 16.08 & 11.4 & 0.43 \\
\hline 24 & 13 & 05 & 14.38 & 11.5 & 25 & 05 & 15.16 & 11.2 & 0.53 \\
\hline 25 & 7 & 03 & 09.71 & 04.6 & 10 & 02 & 18.60 & 12.7 & 0.41 \\
\hline
\end{tabular}

\section{Educational qualifications}

$\begin{array}{llllllllll}\text { SSc (10) } & 2 & 0.8 & 36 & 2.8 & 1 & 0.2 & 7 & - & 0.67 \\ \text { HSc (12) } & 85 & 35 & 15.5 & 11.3 & 188 & 35 & 17.68 & 11.7 & 0.54 \\ \text { Graduate } & 116 & 48 & 15.5 & 11.5 & 249 & 46 & 16.77 & 11.2 & 0.52 \\ \text { PG } & 11 & 4.5 & 21.7 & 19.3 & 76 & 14 & 15.13 & 10.9 & 0.49 \\ \text { Prof } & 29 & 12 & 12.9 & 9.7 & 26 & 4.8 & 13.54 & 9.2 & 0.44\end{array}$

\section{Nature of family}

$\begin{array}{llllllllll}\text { Stay-Self } & 7 & 2.9 & 17.7 & 13.3 & 9 & 1.7 & 19.33 & 8.82 & 0.69 \\ \text { Both Parents } & 158 & 65 & 15.6 & 11.2 & 356 & 66 & 16.7 & 11.6 & 0.49 \\ \text { Father Only } & 2 & 0.8 & 12.5 & 13.4 & 7 & 1.3 & 12.14 & 11.1 & 0.44 \\ \text { Mother Only } & 14 & 5.8 & 17.1 & 12.8 & 39 & 7.2 & 19.38 & 11.9 & 0.67 \\ \text { Separate Parents } & 1 & 0.4 & 9 & - & 6 & 1.1 & 16.83 & 9.5 & 0.57 \\ \text { Parents \& Ext } & 41 & 17 & 14.6 & 11.3 & 92 & 17 & 16.91 & 10.7 & 0.57 \\ \text { Family } & & & & & & & & & \\ \text { Ext Family } & 19 & 7.8 & 17.9 & 16.7 & 28 & 5.2 & 12.82 & 9.1 & 0.47 \\ \text { Stepparents } & 1 & 0.4 & 9 & - & 3 & 0.6 & 10.33 & 4.0 & 0.25\end{array}$

\section{Birth position}

$\begin{array}{llllllllll}\text { Youngest } & 88 & 36 & 16.1 & 12.4 & 175 & 32 & 16.9 & 10.9 & 0.54 \\ \text { Single } & 46 & 19 & 15.8 & 13.3 & 97 & 18 & 15.3 & 11.9 & 0.44 \\ \text { Middle } & 22 & 9.0 & 15.9 & 12.1 & 46 & 8.5 & 16.3 & 11.7 & 0.49 \\ \text { Oldest } & 87 & 36 & 15.1 & 10.23 & 222 & 41 & 17.2 & 11.2 & 0.44\end{array}$

\section{Relationship status}

$\begin{array}{llllllllll}\text { Single } & 184 & 76 & 16.01 & 11.7 & 366 & 68 & 17.3 & 11.5 & 0.54 \\ \text { Casual } & 13 & 5.4 & 15.4 & 15.4 & 26 & 4.8 & 16.9 & 9.7 & 0.51 \\ \text { Committed } & 46 & 19 & 14.4 & 11.1 & 148 & 27 & 15 & 10.9 & 0.46\end{array}$

Hostel stay (in months)

$\begin{array}{llllllllll}0-3 & 175 & 72 & 15.6 & 11.7 & 331 & 61 & 17.4 & 11.3 & 0.54 \\ 4-12 & 21 & 8.6 & 16.6 & 13.7 & 74 & 13 & 14.7 & 10.5 & 0.48 \\ 13-24 & 18 & 7.4 & 20.1 & 15.3 & 60 & 11 & 15.3 & 12.2 & 0.49 \\ 25-36 & 14 & 5.8 & 11.3 & 5.6 & 41 & 7.6 & 15.5 & 10.9 & 0.49 \\ 36+ & 14 & 5.8 & 12.9 & 8.5 & 32 & 5.9 & 18.3 & 10.9 & 0.48\end{array}$

\section{Father education}

\begin{tabular}{llllllllll} 
School & 88 & 36 & 14.99 & 11.7 & 166 & 31 & 18.43 & 11.3 & 0.57 \\
Graduate & 98 & 40 & 16.6 & 12.23 & 232 & 43 & 15.85 & 10.9 & 0.5 \\
PG & 57 & 23 & 15.11 & 10.9 & 142 & 26 & 16 & 11.6 & 0.49 \\
\hline
\end{tabular}


Table 3 (continued)

\begin{tabular}{|c|c|c|c|c|c|c|c|c|c|c|}
\hline \multirow[t]{2}{*}{ Factor } & \multicolumn{4}{|c|}{ Males $(n=243)$} & \multicolumn{4}{|c|}{ Females $(n=540)$} & \multirow[t]{2}{*}{ Dep proportion } & \multirow[t]{2}{*}{$p$-val* } \\
\hline & $n$ & $\%$ & Mean & SD & $n$ & $\%$ & Mean & SD & & \\
\hline Father occupation & & & & & & & & & & 0.16 \\
\hline Unemploy & 7 & 2.9 & 20.7 & 12 & 16 & 3.0 & 22.3 & 13.8 & 0.7 & \\
\hline Self-employed & 99 & 41 & 15.1 & 11.8 & 213 & 39 & 16.6 & 10.9 & 0.54 & \\
\hline Employed & 12 & 46 & 15.7 & 11.3 & 263 & 49 & 16.1 & 11.4 & 0.49 & \\
\hline Retired & 25 & 10 & 16.6 & 13.8 & 48 & 8.9 & 18.5 & 11.2 & 0.56 & \\
\hline Mother education & & & & & & & & & & 0.67 \\
\hline School & 106 & 43 & 15.1 & 11.8 & 188 & 35 & 17.9 & 11 & 0.53 & \\
\hline Graduate & 101 & 42 & 16.8 & 11.8 & 226 & 42 & 16.1 & 11.4 & 0.52 & \\
\hline PG & 36 & 15 & 14.1 & 12 & 126 & 23 & 15.9 & 11.4 & 0.49 & \\
\hline Mother occupation & & & & & & & & & & 0.16 \\
\hline Unemp & 6 & 2.5 & 18.1 & 18.7 & 2 & 0.4 & 4.5 & 3.5 & 0.25 & \\
\hline Self-employed & 27 & 11 & 16.7 & 10.1 & 64 & 12 & 17.7 & 10.9 & 0.57 & \\
\hline Employed & 41 & 17 & 16.9 & 12.9 & 136 & 25 & 16.4 & 11.3 & 0.55 & \\
\hline Retired & 7 & 2.9 & 22 & 16.3 & 9 & 1.7 & 23.4 & 14.3 & 0.69 & \\
\hline Homemaker & 162 & 67 & 14.8 & 11.3 & 329 & 61 & 16.5 & 11.2 & 0.5 & \\
\hline
\end{tabular}

${ }^{*} p$-value calculated between groups BDI $<14$ (no depression) and BDI $>=14$ (has depression) and does not distinguish between gender

(Table 5). Across symptom categories and across gender, sadness, changes in sleep patterns, and concentration difficulties remained the most commonly reported symptoms and with high intensity. It was seen that $49 \%$ of the symptomatic population experienced suicidal thoughts or wishes.

Symptom expression was found to vary with gender (Table 6). Females experienced significantly more somatic symptoms (loss of energy, sleep problems, irritability, appetite problems, concentration, fatigue, loss of interest in sex) than males $(p=0.048)$, though there was no significant difference between genders in the experience of cognitive-affective symptoms.

In participants who were symptomatic $(\mathrm{BDI}>=14)$, symptoms like self-criticalness, punishment feelings, thoughts about past failures, and changes in sleep patterns were significantly more prominent in men, while loss of energy, a somatic symptom, was significantly more prominent in women (Table 7).

Table 4 Prevalence rate of depression according to gender

\begin{tabular}{llllll}
\hline Gender & \multicolumn{2}{l}{ Severity of depression } & Total \\
\cline { 2 - 5 } & $\begin{array}{l}\text { Minimal } \\
(0-13)\end{array}$ & $\begin{array}{l}\text { Mild } \\
(14-19)\end{array}$ & $\begin{array}{l}\text { Moderate } \\
(20-28)\end{array}$ & $\begin{array}{l}\text { Severe } \\
(29-63)\end{array}$ & \\
\hline Male & $125(51 \%)$ & $42(17 \%)$ & $38(16 \%)$ & $38(16 \%)$ & $243(31 \%)$ \\
Mean & 6.65 & 16.26 & 23.21 & 37.13 & 15.67 \\
Female & $252(47 \%)$ & $99(18 \%)$ & $99(18 \%)$ & $90(17 \%)$ & $540(69 \%)$ \\
Mean & 7.11 & 16.74 & 23.55 & 35.84 & 16.68 \\
Total & $377(48 \%)$ & $141(18 \%)$ & $137(17.5 \%)$ & $128(16.3 \%)$ & 783 \\
Mean & 6.96 & 16.60 & 23.46 & 36.22 & 16.36 \\
\hline
\end{tabular}


Table 5 Symptom scores according to severity

\begin{tabular}{|c|c|c|c|}
\hline \multicolumn{2}{|c|}{ Mild, moderate \& severe levels $(\mathrm{BDI}>=14)$} & \multicolumn{2}{|c|}{ Moderate \& severe levels $(\mathrm{BDI}>=20)$} \\
\hline Symptom & Total \% & Symptom & Total \% \\
\hline Changes in sleep patterns & 88.9 & Sadness & 91.3 \\
\hline Sadness & 87.2 & Changes in sleep patterns & 91.3 \\
\hline Concentration difficulties & 86.2 & Concentration difficulties & 89.8 \\
\hline Loss of interest & 82.8 & Loss of energy & 89.4 \\
\hline Loss of energy & 81.5 & Tiredness \& fatigue & 89 \\
\hline Tiredness \& fatigue & 81.3 & Loss of interest & 86.7 \\
\hline Feelings of guilt & 78.8 & Agitation & 86.7 \\
\hline Loss of pleasure & 77.6 & Crying & 86.4 \\
\hline Changes in appetite & 77.6 & Feelings of guilt & 85.6 \\
\hline Irritability & 76.8 & Self criticalness & 84.5 \\
\hline
\end{tabular}

\section{Discussion}

The current study was a descriptive, cross-sectional survey to assess levels of depression in Indian youth aged 19-25 years, living in the state of Maharashtra, India, 8 months into the COVID-19 lockdown. Since the BDI-II was used, scores indicated feelings of depression in the preceding 2 weeks. The study explored associations with several risk factors like gender, age, qualification of the participant, status of hostel stay, relationship status, parental education, and occupational status. Symptomatology of depression among youth was analyzed.

In the present study, depressive symptoms were found in $51.8 \%(n=406)$ of the population, the mean BDI score was 16.48 and the median BDI score was 14, which are both in the mild category. This is in line with pre-COVID studies of adolescent depression from rural Pune (in Maharashtra), where the prevalence rate was found to be $54 \%$ but is much higher than a study from rural Maharashtra, where the prevalence rate among students of ages 12-18 years was found to be $6.66 \%$ (Shaikh et al., 2018; Shelke et al., 2015). Studies of depression from other parts of India have reported wide variations in prevalence rates, ranging from 14.5 to $60 \%$. Hence, although the prevalence is on the higher side, the finding of this study agrees with much of the existing trends from across the country. The mild intensity of depression (mean BDI $=16.48$; Median $=14$ ) found in this study which took place in the middle of the pandemic, is slightly lesser than the moderate level reported by Rehman et al. (2021) in their study of depression in Indian students during the pandemic. Although the complete sequelae of the COVID-19 pandemic may become apparent only after several years, the current study supports existing findings of low to moderate levels of COVID-related distress in adolescents (Magson et al., 2021; Wang et al., 2020).

Table 6 Symptomatology according to gender (BDI $>=14$ )

\begin{tabular}{lccc}
\hline Symptom & $\begin{array}{l}\text { Male } \\
(\text { mean })\end{array}$ & $\begin{array}{l}\text { Females } \\
(\text { mean })\end{array}$ & $p$-value \\
\hline Somatic symptoms & 8.47 & 9.02 & $* 0.048$ \\
Cognitive affective symptoms & 16.74 & 16.03 & 0.287 \\
\hline
\end{tabular}

${ }^{*}$ Significant at 0.05 level 
Table 7 Symptom presentation according to gender $(\mathrm{BDI}>=14)$

\begin{tabular}{llll}
\hline Symptoms & Males (\%) & Females (\%) & $p$-value \\
\hline Self criticalness & 92.10 & 81.4 & $* 0.015$ \\
Punishment feelings & 78.9 & 66.13 & $* 0.020$ \\
Past failures & 84.2 & 73.01 & $* 0.026$ \\
Changes in sleep patterns & 96.05 & 89.4 & $* 0.04$ \\
Loss of energy & 84.21 & 91.5 & $* 0.04$ \\
\hline
\end{tabular}

${ }^{*}$ Significant at 0.05 level

Fluctuations in perception of the pandemic over time as being less dangerous (data collection took place in November when the first wave was coming to an end) may contribute to lower emotional impact (Terry et al., 2020). Several external and intrinsic factors moderate COVID-related depression in young people and a clearer understanding of the experience of depression during the pandemic requires an inquiry into these factors (Porter et al., 2021; Rehman et al., 2021; Sundarasen et al., 2020; Wang et al., 2020).

While some existing community-based studies have found that adolescent depression is largely of mild (Grover et al., 2019; Lodha et al., 2016) or moderate severity (Kumar et al., 2019; Malik et al., 2015), this study found that the symptomatic percentages of mild $(=18 \%)$, moderate $(=17.5 \%)$, and severe $(=16.3 \%)$ categories were almost comparable. The increased intensity of depression may be explained by the fact that this study was conducted almost 8 months into the lockdown, during which time youth had been in a state of prolonged social disconnect. Biological disasters like COVID-19 give rise to acute (within 2-6 months of the outbreak) and long-term (after 6 months of the outbreak) mental health issues. Although they were young and not considered to be a high-risk group during the first wave of the pandemic, college-going youth experienced sudden and dramatic changes in their daily lives during the lockdown. With their regular schedules disrupted, increasing challenges of online education, demands of household responsibilities, rising uncertainty about examinations and career options, and the compulsion to live with restrictions, youth are at higher risk of developing increased distress during the lockdown (Jacob et al., 2020; Magson et al., 2021). Students in higher education experienced ambiguity with regard to immediate and long-term career prospects. Uncertainty about the future has been directly linked to high levels of depression and anxiety (Beck \& Haigh, 2014; Dar et al., 2017; Sundarasen et al., 2020).

Furthermore, as youth mature and their attachment needs are fulfilled through non-familial sources, they have clear preferences for spending more time with their peers. Enforced social isolation and protracted stay with family were twin prongs of the "seismic social shock" caused by the lockdown that has clear implications for mental health (Garnefsky \& Kraaiji, 2009; Magson et al., 2021). At this stage of life, when youth are struggling with identity development, alienation from systemic structures that aid and facilitate identity formation can lead to identity crises, and the individual can feel lost, anxious, and depressed (Andrews, 2016; Commons et al., 2019; Erikson, 1970). The almost equal distribution of participants among mild, moderate, and severe categories may support emerging evidence that pandemicrelated stressors exacerbate over time, leading to a corresponding deterioration of mental health indicators (Magson et al., 2021; Octavius et al., 2020).

In addition to life-stage and pandemic factors, methodological issues related to the study may also have contributed to the high point prevalence recorded. Depression studies based on rating scales have generally reported point prevalence greater than $40 \%$ when compared to studies based on structured instruments, which report a point prevalence rate of $2-25 \%$. 
The findings of this study add weight to existing findings that using a rating scale for a single-stage screening of participants yields higher estimates. A careful assessment of apparent variations in data among states in India needs to be made to get a better understanding of the prevalence of depression among youth in India and results must be interpreted with care (Grover et al., 2019). Standardization of measurement tools, study design, and sample population are imperative for developing nationwide data of mental health indicators before policy decisions are made. The paucity of comparable pre-pandemic data on depression in this population makes it more difficult to delineate the impact of the pandemic and the lockdown accurately.

Assessing for possible risk factors associated with depression, the current study did not find any significant linkages between levels of depression and socio-demographic characteristics such as age, gender, relationship status of participants, birth position, hostel stay, educational status of self and parents, and occupation levels of parents. These findings are inconsistent with the existing association of depression with residency in hostels, belonging to nuclear or joint family systems (Shelke et al., 2015), mothers' education level, and mother's nature of occupation (Lodha et al., 2016). Existing literature has found evidence of the association between female gender and depression before and during the pandemic (Magson et al., 2021; Mishra et al., 2018; Terry et al., 2020; Urmila et al., 2017). Some studies have pointed out possible measurement bias of the BDI to explain females getting higher scores than males, though findings have not been conclusive (de Sá Junior et al., 2019). Contrary to such findings, this study found no significant gender effects, though overall percentages of symptomatic women were slightly more than that of men across mild $(\mathrm{M}=17 \%, \mathrm{~F}=18 \%)$, moderate $(\mathrm{M}=16 \%, \mathrm{~F}=18 \%)$, and severe $(\mathrm{M}=16 \%, \mathrm{~F}=17 \%)$ categories. In their study comparing depression among the youth of Peru, Ethiopia, Vietnam, and India during the pandemic, Porter et al. (2021) found similar results in Indian youth. One reason for variations observed in studies conducted during the pandemic could be the stress-inducing conditions imposed by the pandemic regardless of gender. Alternatively, this finding could support existing evidence that gender effects are more prominent in clinical populations rather than community samples (Compas et al., 1999).

\section{Symptom Profile of Depression}

The BDI measures the somatic and cognitive-affective symptom domains of depression. In this study, substantial heterogeneity was seen in symptom presentation among participants. Across genders, somatic symptoms were significantly more than cognitive-affective symptoms in symptomatic individuals, indicating the important role played by somatic symptoms in the early detection of depression. Somatization is the main reason why patients with depression end up seeking primary care, but it is also the primary cause of undetected depression as it diverts medical attention to other discrete medical conditions (Katon et al., 2004). Hence, there is an urgent need for primary care physicians to assess somatic symptoms with concomitant cognitive-affective symptoms for the early detection of depression in youth. There is growing acceptance of culture as a fundamental factor in the presentation of psychological distress and it has been noted that people in collectivistic cultures have a tendency to somatize distress. People in such cultures commonly present with tiredness, sleep problems, and concentration difficulties when undergoing depression (Ryder et al., 2008). Assessing for depression using the classical Western symptom collection dominated by mood and cognitions may have limited use in such cultural contexts. 
In its wide use with various populations, the BDI-II has thrown up gender differences in symptom presentation, but findings have been inconsistent. The current study adds to this inconsistency. "Changes in sleep patterns" and "sadness" emerged as the most commonly experienced symptoms, although the former has been associated more with women and the latter has been associated more with men (Khesht-Masjedi et al., 2017). Although the means of scores for "difficulty in concentration" and "crying" were higher for females, there were no significant differences across gender, which is in contrast to some studies that have found female gender associated with "difficulties in concentration," "crying," and rumination (Nolen-Hoeksema, 1987; Sund et al., 2001). The mean scores for "guilty feelings" were higher in men than women, which contradicts the finding that women with depression experience more guilt (Silverstein, 2002). Self-criticalness, punishment feelings, and feelings of being a failure were significantly more prominent in symptomatic men than women, lending credence to existing evidence that depression may be "masked" in men due to gender stereotypes and that masculinity in itself may impact how different men experience symptoms of depression. While some studies have found that women score higher than men on both somatic and cognitive-affective scales, others report that such differences may be sensitive to factors like age and the presence of psychological and physiological symptoms (Delisle et al., 2012; Dessotte et al., 2015; Romans et al., 2007; Silverstein, 2002). The current study found that women experienced significantly more somatic symptoms when compared to men, although there was no significant difference in cognitive-affective symptoms. Such disparity has been attributed to biological factors and social aspects like cultural expectations and division of household work. The period of the lockdown has impacted both genders but when compared to men, women and girls face greater social, economic, and health risks. The increased burden of domestic duties and familial expectations like care for family members generally fall on women in collectivistic societies where gender roles are shaped by entrenched patriarchal norms (Davis \& Williamson, 2019; Rivera et al., 2020). Unequal distribution of roles and responsibilities, heightened monitoring and restrictions by family members, reduced personal freedom, increased risks of gender violence, and the perceived inability to challenge gender social norms and disparate power equations could contribute to significant somatic distress in women leading to symptoms like crying, loss of energy, fatigue, and inability to concentrate. Being socially isolated and cut off from supportive social networks and safe spaces due to university closure could add to the vulnerability of women in these cultural contexts, exacerbating somatic symptoms. The interplay of somatic and psychological symptoms has important implications for the personal and professional domains of women's lives. On the one hand, somatic symptoms lead to diagnoses unrelated to depression, while health conditions, related and unrelated to depression, augment depression scores.

Substantial variations in symptom presentation between genders as reported by this study, along with already existing inconsistencies in this area, indicate insufficient empirical support for gender differences in the symptomatology of depression. There is a need to assess whether depression presents itself all that differently in genders, or whether these differences are rooted in individual differences and contextual conditions. Participants of this study were actively engaged in academic and career-related activities and the lockdown may in part account for their keen awareness of difficulties in concentration, sadness, fatigue, disrupted sleep patterns, and self-criticalness triggered by environmental factors like fear about health, excessive media exposure to information about the pandemic, an excessive amount of time spent online, increased workload, and difficulties associated with non-optimal learning experiences during the pandemic including decreased sleep quality due to increased screen time (Salfi et al., 2021). 


\section{Conclusion}

The current study of depression in the youth of Maharashtra found the prevalence rate of depression to be high at $51.8 \%$ and found no association with socio-demographic factors like age, birth position, period of hostel stay, gender, and educational qualifications of participants or their parents, some of which were previously found to be associated with depression. Several socio-cultural factors impact the experience and expression of depression and the differential distribution of these factors across the country may account for such variations. This study was conducted during the COVID-19 pandemic, which was a major stressor for the concerned population. The time period of the study, as well as the nature of tools used, could also lead to variations between studies conducted in India. Regardless, these wide variations demonstrate the need for studies to be conducted according to geographic and demographic factors. The generalizability of such findings to the rest of the nation may be somewhat limited given the wide variations that exist between sections of the population. Future studies in this area must be careful to connect findings to the context and methodological factors, even as they try to collate nationwide data.

There have been very few studies in India that have explored the symptoms of depression experienced by the non-clinical youth population. However, a deeper understanding of the cognitive, affective, and somatic symptoms could be valuable in helping adolescents seek professional care before exacerbation of symptoms. Depression in this critical stage of life can have several long-term consequences for the individual, families, and the community as a whole. In the wake of the uncertainties and stress posed by the ongoing pandemic, it is also important to assess the sources of stress for this age group and devise interventions at the individual and systemic levels, including the family, college and university, potential workplaces, and neighborhoods. As the pandemic rages on and with possibilities of such events in the future, data emerging from such studies could identify protective and mitigating factors while offering keys to ensuring mental health and resilience in youth.

Availability of Data and Material The data that support the findings of this study are available on request from the corresponding author, Mini Narayanan. The data are not publicly available so as to ensure the privacy of research participants].

\section{Declarations}

Ethics Approval Ethical approval for the study was obtained from the Institutional Review Board of the Tata Institute of Social Sciences, Mumbai. The ethical clearance certificate is attached.

Consent to Participate Informed consent was obtained from all individual participants included in the study.

Consent for Publication The participants have consented to the submission of reports for publication.

Conflict of Interest The authors declare no competing interests.

\section{References}

Al-Turkait, F. A., \& Ohaeri, J. U. (2010). Dimensional and hierarchical models of depression using the Beck Depression Inventory-II in an Arab college student sample. BMC Psychiatry, 10, 60. https://doi.org/10. 1186/1471-244X-10-60. PMID: 20670449; PMCID: PMC2918548.

Andrews, M. (2016). The Existential crisis. Behavioral Development Bulletin, 21(1), 104-109. https://doi. org/10.1037/bdb0000014 
Arnett, J. J. (2000). Emerging adulthood a theory of development from the late teens through the twenties. American Psychologist, 55(5), 469-480. https://doi.org/10.1037//0003-066X.55.5.469

Arvind, B. A., Gururaj, G., Loganathan, S., Amudhan, S., Varghese, M., Benegal, V., \& Shibukumar, T. M. (2019). Prevalence and socioeconomic impact of depressive disorders in India: Multisite populationbased cross-sectional study. BMJ Open, 9(6). https://doi.org/10.1136/bmjopen-2018-027250

Aust, F., Diedenhofen, B., Ullrich, S., \& Musch, J. (2013). Seriousness checks are useful to improve data validity in online research. Behavior Research Methods, 45, 527-535. https://doi.org/10.3758/ s13428-012-0265-2.

Ayuso-Mateos, J. L., Vázquez-Barquero, J. L., Dowrick, C., Lehtinen, V., Dalgard, O. S., Casey, P., Wilkinson, C., Lasa, L., Page, H., Dunn, G., Wilkinson, G., \& ODIN Group. (2001). Depressive disorders in Europe: prevalence figures from the ODIN study. The British Journal of Psychiatry, 179(4), 308-316. https://doi.org/10.1192/bjp.179.4.308. PMID: 11581110.

Beck, A. T., \& Haigh, E. (2014). Advances in cognitive theory and therapy: The generic cognitive model. Annual Review of Clinical Psychology, 10, 1-24.

Beck, A. T., Steer, R. A., Ball, R., \& Ranieri, W. (1996). Comparison of Beck Depression Inventories-IA and -II in psychiatric outpatients. Journal of Personality Assessment, 67, 588-597.

Beck, A. T., Steer, R. A., \& Garbin, M. G. (1988). Psychometric properties of the Beck Depression Inventory: Twenty five years of evaluation. Clinical Psychology Review, 8(1), 77-100.

Commons, M. L., Shah, M. J., \& Keffer, M. H. (2019). Using matching "Smarts" and interests to successfully address depression caused by existential crisis. In Cognitive Behavior Therapy. IntechOpen. Retrieved from https://doi.org/10.5772/intechopen.84337

Compas, B. E., Connor, J. K., Saltzman, H., Thomsen, A. H., \& Wadsworth, M. (1999). Getting specific about coping: Effortful and involuntary responses to stress in development. In M. Lewis \& D. Ramsey (Eds.), Soothing and stress (pp. 229-256). Cambridge University Press.

Courtney, D., Watson, P., Battaglia, M., Mulsant, B. H., \& Szatmari, P. (2020). COVID-19 impacts on child and youth anxiety and depression: Challenges and opportunities. Canadian Journal of Psychiatry, 65(10), 688-691. https://doi.org/10.1177/0706743720935646

Dar, K. A., Iqbal, N., \& Mushtaq, A. (2017). Intolerance of uncertainty, depression, and anxiety: Examining the indirect and moderating effects of worry. Asian Journal of Psychiatry, 29, 129-133.

Dardas, L. A., Bailey, D. E., \& Simmons, L. A. (2016). Adolescent depression in the Arab region: A systematic literature review. Issues in Mental Health Nursing, 37, 569-585. https://doi.org/10.1080/01612840. 2016.1177760

Davis, L. S., \& Williamson, C. R. (2019). Does individualism promote gender equality? World Development, 123, 104627. https://doi.org/10.1016/j.worlddev.2019.104627

Delisle, V. C., Abbey, S. E., Beck, A. T., Dobson, K. S., Dozois, D. J., \& Grace, S. L. (2012). The influence of somatic symptoms on Beck Depression Inventory scores in hospitalized postmyocardial infarction patients. Canadian Journal of Psychiatry, 7(12), 752-758.

de Sá Junior, A. R., Liebel G., Andrade, A. G., Andrade, L. H., Gorenstein, C., \& Wang, Y. (2019). Can Gender and Age Impact on Response Pattern of Depressive Symptoms Among College Students? A Differential Item Functioning Analysis. Frontiers of Psychiatry, 10. https://doi.org/10.3389/fpsyt.2019. 00050

Dessotte, C. A. M., Silva, F. S., Furuya, R. K., Ciol, M. A., Hoffman, J. M., \& Dantas, R. A. S. (2015). Somatic and cognitive-affective depressive symptoms among patients with heart disease: Differences by sex and age. Revista Latino-Americana De Enfermagem, 23(2), 208-215. https://doi.org/10.1590/0104-1169. 0287.2544

Erikson, E. H. (1970). On the nature of psycho-historical evidence: In search of Gandhi. In D. A. Rustow, Philosophers and kings: Studies in leadership. George Braziller.

Garnefski, N., \& Kraaij, V. (2009). Cognitive coping and psychological adjustment in different types of stressful life events. Individual Differences Research, 7(3), 168-181.

Grover, S., Dutt, A., \& Avasthi, A. (2010). An overview of Indian research in depression. Indian Journal of Psychiatry, 52(7), 250. https://doi.org/10.4103/0019-5545.69241

Grover, S., Raju, V. V., Sharman, A., \& Shah, R. (2019). Depression in children and adolescents: A review of Indian studies. Indian Journal of Psychological Medicine, 41(3), 216-227.

Hanspal, I., Krishnaswamy, P., Rose, M., Mary, T., Antony, J., \& Johnson, A. R. (2019). How prevalent is depression among rural school-going adolescents: A cross-sectional study in south Karnataka. Journal of Indian Association for Child and Adolescent Mental Health, 15(2), 124-139.

Jacob, P., Rajendra, G. S., \& Sagar, J. V. (2020). Mental health in the times of the COVID - 19 pandemic. In National Institute of Mental Health \& Neurosciences (NIMHANS), 4. https://doi.org/10.36413/pjahs. 0401.005 
Jain, S., Kuppili, P. P., Pattanayak, R. D., \& Sagar, R. (2017). Ethics in psychiatric research: Issues and recommendations. Indian Journal of Psychological Medicine, 39(5), 558-565. https://doi.org/10.4103/ IJPSYM.IJPSYM_131_17

John, R. R., \& John, P. R. (2021). Impact of lockdown on the attitude of university students in South IndiaA cross-sectional observational study. Journal of Maxillofacial and Oral Surgery. https://doi.org/10. 1007/s12663-020-01501-0.

Katon, W. J., Unutzer, J., \& Simon, G. (2004). Treatment of depression in primary care: Where we are, where we can go. Medical Care, 42(2004b), 1153-1157.

Kaur, J., Cheong, S. M., Mahadir Naidu, B., Kaur, G., Manickam, M. A., Mat Noor, M., Ibrahim, N., \& Rosman, A. (2014). Prevalence and correlates of depression among adolescents in Malaysia. Asia Pacific Journal of Public Health, 26(5 Suppl), 53S-62S. https://doi.org/10.1177/1010539514544356. Epub 2014 Jul 28. PMID: 25070697.

Khesht-Masjedi, M. F., Somayeh, S., Elahe, A., Mahbuobe, G., \& Zahra, S. (2017). Comparing depressive symptoms in teenage boys and girls. Journal of Family Medicine and Primary Care, 6(4), 775-779.

Kumar, A., Yadav, G., Chauhan, N., \& Bodat, S. (2019). Prevalence of depression, anxiety and stress among school going adolescent in Chandigarh. International Journal of Community Medicine and Public Health, 6(2), 5021-5026. https://doi.org/10.4103/2249-4863.219988

Lianhmingthangi, C., Harikrishnan, U., \& Sailo, G. L. (2020). Physical and social challenges of youth during lockdown in Mizoram: A COVID lockdown study. International Journal Of Community Medicine And Public Health, 7(12), 4895. https://doi.org/10.18203/2394-6040.ijcmph20205159

Lodha, R. S., Patel, S., Maata, S., Negi, P., Sahu, N., Pal, D. K., \& Murari, L. K. (2016). Prevalence of depression amongst higher secondary school adolescents in Bhopal Madhya Pradesh. National Journal of Community Medicine, 7(11), 856-858.

Magson, N. R., Freeman, J. Y. A., Rapee, R. M., Richardson, C. E., Oar, E. L., \& Fardouly, J. (2021). Risk and protective factors for prospective changes in adolescent mental health during the COVID-19 pandemic. Journal of Youth and Adolescence, 50(1), 44-57. https://doi.org/10.1007/s10964-020-01332-9

Malik, M., Khanna, P., Rohilla, R., Mehta, B., \& Goyal, A. (2015). Prevalence of depression among schoolgoing adolescents in an Urban Area of Bihar, India. International Journal of Community Medicine and Public Health, 2(4), 624-626. https://doi.org/10.4103/0253-7176.207326

Mishra, S. K., Srivastava, M., Tiwary, N. K., \& Kumar, A. (2018). Prevalence of depression and anxiety among children in rural and suburban areas of Eastern Uttar Pradesh: A cross-sectional study. Journal of Family Medicine Primary Care, 7(1), 21-26.

Mohanraj, R., \& Subbaiah, K. (2010). Prevalence of depressive symptoms among urban adolescents of South India. Journal of Indian Association for Child \& Adolescent Mental Health, 2010(6), 33-43.

National Youth Policy. (2003). Ministry of youth affairs and sports. Govt. of India.

NMHS. (2016). National Mental Health Survey of India, 2015-2016 Prevalence, Patterns and Outcomes, Supported by Ministry of Health and Family Welfare, Government of India, and Implemented by National institute of Mental Health and Neurosciences (NIMHANS). Bengaluru: In Collaboration with Partner Institutions; 2015-2016.

Nolen-Hoeksema, S. (1987). Sex differences in unipolar depression: Evidence and theory. Psychological Bulletin, 101(2), 259-282. https://doi.org/10.1037/0033-2909.101.2.259

Octavius, G. S., Silviani, F. R., Lesmandjaja, A., \& Juliansen, A. (2020). Impact of COVID-19 on adolescents' mental health: A systematic review. Middle East Current Psychiatry, 27(1), 4-11. https://doi. org/10.1186/s43045-020-00075-4.

Özdin, S., \& Özdin, Ş. B. (2020). Ozdin_Depression.pdf. International Journal of Social Psychiatry, 66(5), 504-511.

Pandian, R. D., Sreeranjini, T., Aiman, A., John, S., Shishir, K., \& Prabhu, S. (2017). A study on the prevalence of depression among young adults in South India. Indian Journal of Mental Health(IJMH), 4(1), 24. https://doi.org/10.30877/ijmh.4.1.2017.24-29

Patra, S., \& Patro, B. K. (2020). COVID-19 and adolescent mental health in India. The Lancet Psychiatry, 12(7), 1015, December 01, 2020. https://doi.org/10.1016/S2215-0366(20)30461-2

Porter, C., Favara, M., Hittmeyer, A., Scott, D., Sánchez Jiménez, A., Ellanki, R., \& Stein, A. (2021). Impact of the COVID-19 pandemic on anxiety and depression symptoms of young people in the global south: Evidence from a four-country cohort study. British Medical Journal Open, 11(4), 1-14. https://doi.org/ 10.1136/bmjopen-2021-049653

Rehman, U., Shahnawaz, M. G., Khan, N. H., Kharshiing, K. D., Khursheed, M., Gupta, K., \& Uniyal, R. (2021). Depression, anxiety and stress among Indians in times of Covid-19 lockdown. Community Mental Health Journal, 57(1), 42-48. https://doi.org/10.1007/s10597-020-00664-x

Rezvan, A., \& D’Souza, L. (2017). Influence of parenting styles on shyness among adolescents. European Online Journal of Natural and Social Sciences, 5(1), 667-673. https://doi.org/10.25215/0501.106 
Rivera, C., Hsu, Y.-C., Esbry, F. P., \& Dugarova, E. (2020). Gender inequality and the COVID-19 crisis: A human development perspective. UNDP.

Romans, S. E., Tyas, J., Cohen, M. M., \& Silverstone, T. (2007). Gender differences in the symptoms of major depressive disorder. The Journal of Nervous and Mental Disease, 195(11), 05-11.

Ryder, A., Yang, J., Zhu, X., Yao, S., Yi, J., Heine, S., \& Bagby, R. (2008). The cultural shaping of depression: Somatic symptoms in China, psychological symptoms in North America?. Journal of Abnormal Psychology, 117, 300-13. https://doi.org/10.1037/0021-843X.117.2.300

Sagar, R., Dandona, R., Gururaj, G., Dhaliwal, R. S., Singh, A., Ferrari, A., \& Dandona, L. (2020). The burden of mental disorders across the states of India: The Global Burden of Disease Study 1990-2017. The Lancet Psychiatry, 7(2), 148-161. https://doi.org/10.1016/S2215-0366(19)30475-4

Salari, N., Hosseinian-Far, A., Jalali, R., Vaisi-Raygani, A., Rasoulpoor, S., Mohammadi, M., \& KhalediPaveh, B. (2020). ى ى Globalization and Health, 16(1), 1-11.

Salfi, F., Amicucci, G., Corigliano, D., D’Atri, A., Viselli, L., Tempesta, D., \& Ferrara, M. (2021). Changes of evening exposure to electronic devices during the COVID-19 lockdown affect the time course of sleep disturbances. National Library of Medicine. 2021 May 26:zsab080. https://doi.org/10.1093/ sleep/zsab080. Epub ahead of print. PMID: 34037792 ; PMCID: PMC8194574.

Shaikh, B. M., Doke, P. P., \& Gothankar, J. S. (2018). Depression, anxiety, stress, and stressors among rural adolescents studying in Pune and a rural block of Nanded district of Maharashtra. India. Indian Journal of Public Health, 62(4), 311-314. https://doi.org/10.4103/ijph.IJPH_174_17

Shelke, U. S., Kunkulol, R. R., Phalke, V. D., Narwane, S. P., \& Patel, P. C. (2015). Study of depression among adolescent students of rural Maharashtra and its association with socio-demographic factors: A cross-sectional study. International Journal of Medical Research \& Health Sciences, 4(1), 41-45.

Silverstein, B. (2002). Gender differences in the prevalence of somatic versus pure depression: A replication. American Journal of Psychiatry, 159, 1051-1052.

Singh, M. M., Gupta, M., \& Grover, S. (2017). Prevalence \& factors associated with depression among schoolgoing adolescents in Chandigarh, north India. Indian Journal of Medical Research, 146(August), 205-215. https://doi.org/10.4103/ijmr.IJMR

Sund, A. M., Larsson, B., \& Wichstrøm, L. (2001). Depressive symptoms among young Norwegian adolescents as measured by the Mood and Feelings Questionnaire (MFQ). European Child and Adolescent Psychiatry, 10(4), 222-229. https://doi.org/10.1007/s007870170011

Sundarasen, S., Chinna, K., Kamaludin, K., Nurunnabi, M., Baloch, G. M., Khoshaim, H. B., \& Sukayt, A. (2020). Psychological impact of covid-19 and lockdown among university students in Malaysia: Implications and policy recommendations. International Journal of Environmental Research and Public Health, 17(17), 1-13. https://doi.org/10.3390/ijerph17176206

Terry, P. C., Parsons-Smith, R. L., \& Terry, V. R. (2020). Mood responses associated with COVID-19 restrictions. Frontiers in Psychology, 11, 1-10. https://doi.org/10.3389/fpsyg.2020.589598

Urmila, K. V., Usha, K., Mohammed, M., \& Pavithran, K. (2017). Prevalence and risk factors associated with depression among higher secondary school students residing in a boarding school of North Kerala, India. International Journal of Contemporary Pediatrics, 4(3), 735. https://doi.org/10.18203/ 2349-3291.ijcp20171072

Wang, C., Pan, R., Wan, X., Tan, Y., Xu, L., Ho, C. S., \& Ho, C. R. (2020). Immediate psychological responses and associated factors during the initial stage of the 2019 coronavirus disease (COVID-19) epidemic among the general population in China. International Journal of Environmental Research and Public Health, 17(5), 1729. https://doi.org/10.3390/ijerph17051729

Wang, Y. -P., \& Gorenstein, C. (2013). Psychometric properties of the Beck Depression Inventory-II: A comprehensive review. Revista Brasileira de Psiquiatria, 35(4), 416-431. https://doi.org/10.1590/ 1516-4446-2012-1048

Ward, M. K., \& Pond, S. B. (2015). Using virtual presence and survey instructions to minimize careless responding on Internet-based surveys. Computers in Human Behavior, 48, 554-568. https://doi.org/10. 1016/j.chb.2015.01.070

Win, K. L., Kawakami, N., \& Doe, G. H. (2019). Factor structure and diagnostic efficiency of the Myanmar version BDIII among substance users. Annals of General Psychiatry, 18, 12. https://doi.org/10.1186/ s12991-019-0236-4

Yang, L., Zhao, Y., Wang, Y., Liu, L., Zhang, X., Li, B., \& Cui, R. (2015). The effects of psychological stress on depression. Current Neuropharmacology, 13(4), 494-504. https://doi.org/10.2174/ $1570159 \times 1304150831150507$

Publisher's Note Springer Nature remains neutral with regard to jurisdictional claims in published maps and institutional affiliations. 